January 2022

\title{
Relationship Between Estimated V02max and Handgrip Strength in Healthy Young Nigerian Adults
}

Oluwatobiloba Ajepe

University of Lagos, tigbari@unilag.edu.ng

Nnamdi Mgbemena

James Cook University, nnamdi.mgbemena@my.jcu.edu.au

Udoka Okafor

University of Lagos, uacokafor@cmul.edu.ng

Oluwatosin Ehuwa

University of Lagos, tosynfunmilayo@gmail.com

Chukwuebuka Okeke

Nnamdi Azikiwe University, ptokekeolisa@gmail.com

See next page for additional authors

Follow this and additional works at: https://nsuworks.nova.edu/ijahsp

Part of the Physiotherapy Commons, and the Sports Sciences Commons

\section{Recommended Citation}

Ajepe O, Mgbemena N, Okafor U, Ehuwa O, Okeke C, Osundiya O, et al. Relationship Between Estimated VO2max and Handgrip Strength in Healthy Young Nigerian Adults. The Internet Journal of Allied Health Sciences and Practice. 2022 Jan 03;20(1), Article 17.

This Manuscript is brought to you for free and open access by the College of Health Care Sciences at NSUWorks. It has been accepted for inclusion in Internet Journal of Allied Health Sciences and Practice by an authorized editor of NSUWorks. For more information, please contact nsuworks@nova.edu. 


\title{
Relationship Between Estimated V02max and Handgrip Strength in Healthy Young Nigerian Adults
}

\begin{abstract}
Purpose: This study investigated the relationship between estimated oxygen consumption $\left(\mathrm{VO}_{2} \mathrm{max}\right)$ and handgrip strength (HGS) among healthy young Nigerian adults. Methods: This was a cross sectional study, which involved 400 volunteers (171 males; 229 females) aged between 18-40years. Participants' HGS was assessed using a CAMRY EH-101 hand dynamometer while $\mathrm{VO}_{2}$ max was estimated using a standard formula that includes measurement of resting heart rate. Demographic data was summarized using percentages, mean and standard deviation. Physical activity level of the participants was assessed using long form of the International Physical Activity Questionnaire. Independent t-test was used to compare the mean values of the variables between male and female participants. Pearson's correlation was used to determine the strength of relationship between estimated $\mathrm{VO}_{2}$ max and HGS, while multiple regression analysis was conducted to determine the predictors of estimated $\mathrm{VO}_{2}$ max using $\mathrm{HGS}$ as well as body mass index (BMI), physical activity (PA) level, age and sex as co-variates. Level of significance was set at $p<0.05$. Results: $\mathrm{HGS}, \mathrm{VO}_{2}$ max and PA level were significantly $(p=0.001)$ different between male and female participants. There was a significant moderate correlation between $\mathrm{HGS}$ and $\mathrm{VO}_{2} \mathrm{max}$ $(r=0.40, p=0.001)$. The results of the regression analysis showed that HGS is not significant predictor of estimated $\mathrm{VO}_{2}$ max; whereas, sex, $\mathrm{BMI}$ and PA level were significant predictors of estimated $\mathrm{VO}_{2}$ max. Conclusion: Although HGS is moderately correlated with estimated $\mathrm{VO}_{2}$ max, $\mathrm{HGS}$ may not be a relevant tool for predicting estimated $\mathrm{VO}_{2}$ max in healthy young adults.
\end{abstract}

\section{Author Bio(s)}

Titilope O. Ajepe, Ph.D, is a lecturer in the Department of Physiotherapy, College of Medicine, University of Lagos, Nigeria.

Nnamdi C. Mgbemena, MSc.PT, is a Ph.D candidate in the College of Healthcare Sciences, James Cook University, Australia.

Udoka C. Okafor, Ph.D, is a senior lecturer in the Department of Physiotherapy, College of Medicine, University of Lagos, Nigeria

Oluwatosin O. Ehuwa, B.PT, is a graduate physiotherapist from the Department of Physiotherapy, College of Medicine, University of Lagos, Nigeria.

Chukwuebuka O. Okeke, MSc.PT, is a lecturer in the Department of Physiotherapy, Nnamdi Azikiwe University, Nigeria.

Oladuni C. Osundiya, Ph.D, is a lecturer in the Department of Physiotherapy, College of Medicine, University of Lagos, Nigeria

Jeremiah P. Oyedemi, B.PT, is a graduate physiotherapist from the Department of Physiotherapy, College of Medicine, University of Lagos, Nigeria

Chidinma J. Ezeugwa, MSc.PT, is a graduate assistant and also a Ph.D student in the Department of Physiotherapy, College of Medicine, University of Lagos, Nigeria

\section{Acknowledgements}

Authors would like than appreciate all the students who voluntarily participated in this study. This research 
did not receive any specific grant from funding agencies in the public, commercial, or not-for-profit sectors.

\section{Authors}

Oluwatobiloba Ajepe, Nnamdi Mgbemena, Udoka Okafor, Oluwatosin Ehuwa, Chukwuebuka Okeke, Oladuni Osundiya, Jeremiah Oyedemi, and Chidinma Ezeugwa 


\title{
1UAHSP \\ The Internet Joumnal of Allied Health Sciences and Practice \\ Dedicated to allied health professional practice and education \\ Vol. 20 No. 1 ISSN 1540-580X
}

\section{Relationship Between Estimated $\mathrm{VO}_{2}$ max and Handgrip Strength in Healthy Young Nigerian Adults}

\author{
Oluwatobiloba Ajepe ${ }^{1}$ \\ Nnamdi Mgbemena² \\ Udoka Okafor ${ }^{1}$ \\ Oluwatosin Ehuwa ${ }^{1}$ \\ Chukwuebuka Okeke ${ }^{3}$ \\ Oladuni Osundiya ${ }^{1}$ \\ Jeremiah Oyedemi ${ }^{1}$ \\ Chidinma Ezeugwa ${ }^{1}$ \\ 1. University of Lagos \\ 2. James Cook University \\ 3. Nnamdi Azikiwe University \\ Nigeria and Australia
}

\begin{abstract}
Purpose: This study investigated the relationship between estimated oxygen consumption $\left(\mathrm{VO}_{2} \mathrm{max}\right)$ and handgrip strength (HGS) among healthy young Nigerian adults. Methods: This was a cross sectional study, which involved 400 volunteers (171 males; 229 females) aged between 18-40years. Participants' HGS was assessed using a CAMRY EH-101 hand dynamometer while $\mathrm{VO}_{2}$ max was estimated using a standard formula that includes measurement of resting heart rate. Demographic data was summarized using percentages, mean and standard deviation. Physical activity level of the participants was assessed using long form of the International Physical Activity Questionnaire. Independent t-test was used to compare the mean values of the variables between male and female participants. Pearson's correlation was used to determine the strength of relationship between estimated $\mathrm{VO}_{2}$ max and $\mathrm{HGS}$, while multiple regression analysis was conducted to determine the predictors of estimated $\mathrm{VO}_{2}$ max using $\mathrm{HGS}$ as well as body mass index (BMI), physical activity (PA) level, age and sex as covariates. Level of significance was set at $p<0.05$. Results: $\mathrm{HGS}, \mathrm{VO}_{2}$ max and PA level were significantly $(p=0.001)$ different between male and female participants. There was a significant moderate correlation between $\mathrm{HGS}$ and $\mathrm{VO}_{2} \max (r=0.40, p=$ 0.001). The results of the regression analysis showed that HGS is not significant predictor of estimated $\mathrm{VO}_{2}$ max; whereas, sex, BMI and PA level were significant predictors of estimated $\mathrm{VO}_{2}$ max. Conclusion: Although HGS is moderately correlated with estimated $\mathrm{VO}_{2}$ max, $\mathrm{HGS}$ may not be a relevant tool for predicting estimated $\mathrm{VO}_{2}$ max in healthy young adults.
\end{abstract}

Key words: handgrip strength, cardio-respiratory capacity, $\mathrm{VO}_{2} \max$, healthy adults 


\section{INTRODUCTION}

Physical fitness is considered as an integrated measure of all body functions and structures during physical activity (PA) and/or exercise. ${ }^{1}$ This measure, which is partly determined by genetic or environmental factors, could be classified as skill- or healthrelated, with the latter primarily related to functional health and disease prevention. ${ }^{2}$ Among the five health-related fitness components, cardiorespiratory fitness (CRF) and muscular fitness are most widely studied due to their strong relationships with healthy outcomes. ${ }^{3}$ Cardiorespiratory fitness is the ability of the respiratory and cardiovascular systems of the body to carry out prolonged moderate to vigorous exercises, with factors such as, age, male sex, body mass index (BMI) and PA reported to influence $\mathrm{CRF}^{2,4}$

According to World Health Organisation (WHO), maximal oxygen consumption $\left(\mathrm{VO}_{2} \mathrm{max}\right)$ is reported as the standard indicator for assessing CRF. During maximal or submaximal exercise, some direct methods have been identified for determining $\mathrm{VO}_{2}$ max, while several indirect methods have also been reported for estimating $\mathrm{VO}_{2}$ max. ${ }^{5,6}$ Following this, a plethora of studies have reported the relevance of higher CRF in improving health outcomes. For instance, increased CRF has been associated with decreased cardiovascular events and cancer, with muscular fitness adding to the protective outcomes of CRF against cancer deaths. ${ }^{7-9}$

Muscular fitness is a combined function of muscle strength, muscle endurance and muscle power. ${ }^{10}$ Assessment of isometric muscle strength using handgrip strength (HGS) is one of the most cited test batteries for assessing muscular fitness, and this could be due to its easy-to-use nature, high reliability and validity in healthy and unhealthy populations. ${ }^{3,11}$ Similarly, several studies have reported an association between stronger HGS and some health outcomes such as better health-related quality of life, increased lung function and decreased mortality from cardiovascular and respiratory diseases across different age groups. ${ }^{12-14}$

Previously, Sugie et al reported a moderate association between $\mathrm{HGS}$ and $\mathrm{VO}_{2}$ max in unhealthy older adults. ${ }^{15}$ Confirmation of this association in healthy and younger population may inform the predictive ability of $\mathrm{HGS}$ for $\mathrm{VO}_{2}$ max by allied health professionals and physical educators. However, in low to middle income countries (LMICs), direct assessment of $\mathrm{VO}_{2} \mathrm{max}$ using expensive laboratory equipment and trained professionals may not be practicable due to financial constraints. This shortfall calls for consideration of alternative methods for estimating $\mathrm{VO}_{2}$ max in such countries. Therefore, the aim of this study


if $\mathrm{HGS}$ is a significant predictor of estimated $\mathrm{VO}_{2} \mathrm{max}$ in these adults.

\section{MATERIALS AND METHODS}

This study was approved by the Health Research and Ethics Committee of the College of Medicine, University of Lagos. Written informed consent was obtained from each participant prior to participating in the study.

\section{Participants}

Participants were healthy young adults aged between 18 and 40 years, who were students at the University of Lagos (both Akoka and Idi-Araba campuses), Lagos State, Nigeria. Prior to data collection, students filled-out a short form to screen for their eligibility. Participants were considered "healthy" if they reported not having any chronic disease condition such as diabetes, hypertension etc. Also, students who had known respiratory disorders, upper limb deformity/injury, previous surgery in the hand or forearm in the last three months and neurological disorders of the upper limbs were excluded from the study.

\section{Protocol}

A cross-sectional design was adopted in this study. Random sampling technique using the Fish Bowl method was used to recruit the participants. From the list of all faculties in the University, two faculties were selected. From these two faculties, two departments each (four departments in total) were picked. Two levels of study were selected from each department (eight levels in total). Finally, 50 students were randomly selected (using computer generated numbers) from each level, which yielded a total of four hundred (400) students. Information on participants' demographics was obtained using a short form and variables such as weight, height and body mass index (BMI) were assessed. BMI was categorized as underweight $\left(<18.5 \mathrm{~kg} / \mathrm{m}^{2}\right)$, normal $\left(18.5-24.9 \mathrm{~kg} / \mathrm{m}^{2}\right)$, overweight $\left(25-29.9 \mathrm{~kg} / \mathrm{m}^{2}\right)$ and obese $\left(\geq 30 \mathrm{~kg} / \mathrm{m}^{2}\right) .16$

\section{Assessment of Handgrip Strength}

A digital hand dynamometer (CAMRY EH-101, USA) was used to assess the HGS (in kilograms). Previously, excellent testretest reliability $(0.91-0.98)$ has been reported for this device. ${ }^{17}$ Using the guidelines by the American Society of Hand Therapists, participants sat comfortably on a chair without an arm rest and those who wore wrist watches were advised to remove them before the test. While seated, the participants adducted their shoulders to the side, elbows flexed to $90^{\circ}$, forearms and wrists placed in neutral position, while their feet were placed flat on the ground. ${ }^{18}$ The researcher demonstrated the testing procedures to the participants. The participants were instructed to squeeze the dynamometer maximally up to six seconds. Three trials of HGS testing were conducted for only the dominant hand, with a 15-second rest period between trials. The 
dominant hand was determined by asking the participants which hand they use more frequently in carrying-out their activities of daily living.

\section{Estimation of $\mathrm{VO}_{2} \max$}

Estimates of participant's $\mathrm{VO}_{2}$ max was determined using the Heart Rate Ratio method (HRR-method). ${ }^{19}$ After HGS assessment, participants remained seated for five minutes to allow their heart rates return to resting levels. Resting heart rate (HRrest) was calculated by palpating for the radial pulse for 30 seconds, then multiplying the value by 2 . However, a minimal error of 1.10 has been previously identified for determining HRrest using this method. ${ }^{20}$ The maximal heart rate (HRmax) was predicted using the participant's age (years) in the formula, $\mathrm{HR}_{\max }=208-\left(0.7 \times \mathrm{Age}\right.$ ) (years). ${ }^{21} \mathrm{~A}$ final computation for $\mathrm{VO}_{2} \mathrm{max}$ in millilitre per kilogram per minute $(\mathrm{mL} / \mathrm{kg} / \mathrm{min})$ was performed using the formula, $\mathrm{VO}_{2} \mathrm{max}(\mathrm{mL} / \mathrm{kg} / \mathrm{min}) .=15.3 \mathrm{x}$ $\left(H R_{\max } / H R_{\text {rest) }}\right)^{19}$ Previously, a study reported a good agreement (ranging up to $3.14 \mathrm{~mL} / \mathrm{kg} / \mathrm{min}$ ) between the HRR-method and direct measurement of $\mathrm{VO}_{2} \mathrm{max}$ in Indian university students. ${ }^{22}$ However, reliability reports using the HRR-method in Nigerian population is lacking.

\section{Determination of Physical Activity Levels}

The long form of the International Physical Activity Questionnaire (IPAQ-LF) was used to assess the PA levels of the participants. This IPAQ-LF consists of 27 questions, which could be interviewed through telephone, interviewed in person or self-administered to adults (aged $15-69$ years) across different socio-economic groups. ${ }^{23}$ This questionnaire provided information on activities conducted in the last seven days within four domains that may be related to physical activity. ${ }^{23}$ Previously, a language-modified version of the IPAQ-LF has been reported to show a good reliability and moderate construct validity in assessing PA in Nigerian adults. ${ }^{24}$ All IPAQ raw data (expressed in MET/minutes/week) of the participants was categorized into sedentary, moderate or high PA level using the cut-off points from the IPAQ scoring protocol. ${ }^{25}$

\section{Data Analysis}

Demographic data were summarized using mean and standard deviations. Independent t-test was used to compare the mean values of the variables between male and female participants. Pearson's correlation coefficient was used to determine the strength of relationship between $\mathrm{VO}_{2}$ max and HGS. Pearson correlation coefficient $(r)$ values of $<0.3,0.3-0.7$ and $>0.7$ were interpreted as weak, moderate and strong relationships, respectively. ${ }^{26}$ Multiple regression analysis was conducted to determine the prediction of $\mathrm{VO}_{2}$ max (dependent variable) using $\mathrm{HGS}$ with age, sex, $\mathrm{BMI}$ and PA level (independent variables) as co-variates. These co-variates were considered since prior studies have reported significant association with $\mathrm{VO}_{2} \mathrm{max} .{ }^{26}$ Physical activity levels were initially coded as $1=$ high (active); $2=$ moderate (moderate) and 3=low (sedentary), however, dummy variables (PAhigh and PAmoderate) were created for PA levels to fit into multiple regression analysis using PAlow as the reference variable. All assumptions of multiple regression analysis were met. All statistical tests were performed using SPSS version 22 (IBM, Chicago, USA) with the level of significance set at $<0.05$.

\section{RESULTS}

\section{Demographic Data of the Participants}

Four hundred (57\% females) healthy adults aged $18-40$ years, participated in the study. The mean age, height, weight, BMI, $\mathrm{VO}_{2}$ max and $\mathrm{HGS}$ of all participants are as shown on Table 1. Results of the BMI classification described $55(14 \%)$ participants as underweight, $279(70 \%)$ as normal and $66(16 \%)$ as overweight. Further, independent t-test showed significant $(p<0.05)$ differences in height, weight, $\mathrm{VO}_{2}$ max and HGS between males and females (Table 1).

Table 1. Demographic Characteristics, $\mathrm{HGS}$, and Estimated $\mathrm{VO}_{2}$ max of the Participants

\begin{tabular}{|c|c|c|c|c|c|}
\hline Variables & $\begin{array}{l}\text { Total }(n=400) \\
\text { Mean (SD) }\end{array}$ & $\begin{array}{l}\text { Males }(n=171) \\
\text { Mean (SD) }\end{array}$ & $\begin{array}{l}\text { Females }(n=229) \\
\text { Mean (SD) }\end{array}$ & $\mathrm{t}$-value & $p$-value \\
\hline Age (years) & $22.95(4.66)$ & $23.44(4.43)$ & $22.58(4.80)$ & 1.849 & 0.065 \\
\hline Height (m) & $1.70(0.11)$ & $1.76(0.11)$ & $1.66(0.09)$ & 9.229 & 0.001 \\
\hline Weight (kg) & $63.05(11.23)$ & $67.13(10.2)$ & $60.00(11.07)$ & 6.609 & 0.001 \\
\hline BMI $\left(\mathrm{kg} / \mathrm{m}^{2}\right)$ & $21.73(3.60)$ & $21.82(3.25)$ & $21.6(3.86)$ & 0.414 & 0.679 \\
\hline PA low (n) & 55 & 17 & 38 & & \\
\hline PA Moderate $(\mathrm{n})$ & 279 & 132 & 147 & & \\
\hline PA high (n) & 66 & 22 & 44 & & \\
\hline $\mathrm{VO}_{2} \max (\mathrm{m} / \mathrm{kg} / \mathrm{min})$ & $38.35(5.44)$ & $40.97(5.73)$ & $36.38(4.28)$ & 8.690 & 0.001 \\
\hline HGS (kg) & $31.78(10.03)$ & $38.84(10.50)$ & $26.50(5.34)$ & 15.210 & 0.001 \\
\hline
\end{tabular}

Key: BMI - body mass index; HGS - handgrip strength; $\mathrm{m}$ - meters; $\mathrm{kg}$ - kilogram; $\mathrm{VO}_{2} \mathrm{max}$ - estimated maximum oxygen consumption; $\mathrm{SD}$ - standard deviation; $\mathrm{n}$ - frequency; PA - physical activity; $\mathrm{t}$-value - independent t-test values; $\mathrm{m} / \mathrm{kg} / \mathrm{min}$ - millilitres per kilogram per minute; $p$ - significance level at $<0.05$. 
Prediction of $\mathrm{VO}_{2} \max$ of the Participants using HGS Measurement:

Pearson correlation analysis showed that there was a moderate significant positive correlation between $\mathrm{VO}_{2} \mathrm{max}$ and $\mathrm{HGS}$ $(r=0.40 ; p=0.001 ; 95 \% \mathrm{Cl}: 0.28-0.52)$ for all the participants. Multiple regression analysis to predict $\mathrm{VO}_{2}$ max showed that HGS and age were not significant predictors, while sex, BMI and PA levels of the participants were shown to be significant predictors (Table 2). Coefficient of determination $\left(\mathrm{R}^{2}\right)$ involving sex, $\mathrm{BMI}$ and $\mathrm{PA}$ levels as predictors for $\mathrm{VO}_{2}$ max was 0.634 , which indicated that about $63.4 \%$ of the variability in $\mathrm{VO}_{2}$ max can be explained by sex, $\mathrm{BMl}$ and PA levels of the participants. We generated the regression equation for predicting estimated $\mathrm{VO}_{2} \max : \mathrm{VO}_{2} \max =34.769+1.786$ (Sex) $0.113(\mathrm{BMI})+12.651$ (PAhigh) +5.763 (PAmoderate) Note that the reference group for sex is females and for physical activity level is PAlow.

Table 2. Regression Variables for Predicting Estimated $\mathrm{VO}_{2}$ max using HGS and Other Covariates.

\begin{tabular}{lllll}
\hline Variables & $\beta$ & Std Error & $B$ & $p$ \\
\hline Intercept & 34.769 & 1.413 & & 0.001 \\
HGS & 0.019 & 0.022 & 0.034 & 0.401 \\
Age & -0.046 & 0.039 & -0.038 & 0.243 \\
Sex & 1.786 & 0.444 & 0.159 & 0.001 \\
BMl & -0.113 & 0.049 & -0.073 & 0.022 \\
PAhigh & 12.651 & 0.628 & 0.885 & 0.001 \\
PAmoderate & 5.763 & 0.471 & 0.502 & 0.001 \\
\hline
\end{tabular}

Key: HGS - handgrip strength; BMI - body mass index; PA level physical activity level; $\beta$ - unstandardized coefficient; Std Error - standard error of the coefficient; B - standardized coefficient; $p$ - significance level at $<0.05$.

\section{DISCUSSION}

This study was conducted to investigate the relationship between estimated $\mathrm{VO}_{2}$ max and $\mathrm{HGS}$ in healthy young adults. The findings of this study showed that HGS had a moderate correlation with estimated $\mathrm{VO}_{2} \mathrm{max}$. Despite the relationship between HGS and estimated $\mathrm{VO}_{2}$ max, HGS was not a significant predictor for estimated $\mathrm{VO}_{2}$ max. However, sex, BMI and PA levels were identified as significant predictors for estimated $\mathrm{VO}_{2}$ max. From our robust search of literature, no study has reported on the relationship between $\mathrm{VO}_{2}$ max and HGS in healthy young adults LMICs. The findings of this study showed that in healthy young adults living in a LMICs such as Nigeria, where indirect estimation of $\mathrm{VO}_{2}$ max is preferably conducted due to financial constraints, a cheaper and easy-to-use tool such as HGS may not be a suitable and quick indicator of estimated $\mathrm{VO}_{2}$ max.

Evaluation of HGS of the participants showed that males had significantly stronger HGS compared to the females. This finding was in accordance with results of previous studies (locally and internationally), which suggest that increased grip strength in males could be explained by a combined effect of genetic and environmental factors. 27,28 Male sex hormones such as testosterone has been associated with increased satellite cells (precursors of skeletal muscle cells) and overgrowth of Type 1 and 2 muscles fibers, thereby yielding stronger muscle contraction during gripping.29,30 Lifestyle factors such as smoking, alcohol consumption, nutritional status and PA, where males are reported to be more likely involved in PA than females, have all been associated with $\mathrm{HGS} .{ }^{31,32}$ Similarly, estimated $\mathrm{VO}_{2}$ max mean values were shown to be significantly higher in males than in females, which confirms the results of previous studies. ${ }^{33-35}$ This difference in estimated $\mathrm{VO}_{2}$ max could be explained by physiological and behavioural factors such as men having higher haemoglobin $(\mathrm{Hb})$ levels, lower percentage body fat (\%BF), higher lean body mass, larger size of heart and increased involvement in habitual PA than their female counterparts. ${ }^{30}$

Evaluation of the relationship between $\mathrm{HGS}$ and estimated $\mathrm{VO}_{2}$ max showed a moderate association, and this agrees with previous finding in elderly community-dwellers. ${ }^{15}$ The reported associations in this study could be attributed to the PA levels of the students with a majority of the students engaged in low to moderate physical activities (81.5\%). Reduced involvement in PA have been related to increased adiposity and increased systemic inflammatory biomarkers, such as interleukin-6 (IL-6) and creatinine reactive protein (CRP). ${ }^{36}$ These biomarkers are inversely proportional to insulin-like growth factor-1, which causes reduced muscle mass and subsequently, weaker skeletal muscle strength. ${ }^{37}$ Similarly, circulating levels of IL- 6 and $\mathrm{CRP}$ have been linked with reduced $\mathrm{VO}_{2}$ max in adults, with engagement in PA reported to reverse the level of inflammatory markers. 38,39

Typically, direct assessment of $\mathrm{VO}_{2} \mathrm{max}$ is conducted in exercise laboratories using standardized protocols with expensive equipment such treadmills and cycle ergometers. However, in LMICs, these direct tests are not usually practical, which warrant the use of other methods for estimating $\mathrm{VO}_{2}$ max in these countries. The current study showed that a simple test such a HGS is not a relevant tool in predicting estimated $\mathrm{VO}_{2}$ max in healthy young adults. This finding may be attributed to HGS being a more isolated (upper limb) strength test while estimated $\mathrm{VO}_{2}$ max is more holistic, which estimates the maximal oxygen uptake by the entire body during exercise. Further, identification of sex, BMI and PA levels as significant factors explaining $63.4 \%$ variability in $\mathrm{VO}_{2} \mathrm{max}$ suggests that there are other factors such as ethnicity that could be contributing to this variation. ${ }^{40}$ Therefore, a simple test like HGS may be of poor clinical relevance in predicting estimated $\mathrm{VO}_{2}$ max in healthy young adults. 


\section{Study Limitations}

The cross-sectional design of this study and the involvement of students within 18 - 40 years may have limited the ability to predict estimated $\mathrm{VO}_{2} \max$ and generalise our findings to other healthy adults of older ages and different ethnicities. Future research may consider conducting longitudinal studies across wider age ranges, while accounting for other covariates of $\mathrm{VO}_{2}$ max such as; $\mathrm{Hb}$ levels, \%BF, lean body mass and ethnicity, in order to further explain the association between HGS and $\mathrm{VO}_{2}$ max and its predictability.

\section{CONCLUSION}

Handgrip strength is associated with estimated $\mathrm{VO}_{2} \mathrm{max}$, but not a significant predictor of the latter. Use of a simple and noninvasive tool such as HGS may not be suitable indicator of CRF in healthy young adults living in a low resource country.

\section{REFERENCES}

1. Fonseca Del Pozo FJ, Alonso JV, Álvarez MV, Orr S, Cantarero FJL. Physical fitness as an indicator of health status and its relationship to academic performance during the prepubertal period. Health Promot Perspect. 2017;7(4):197204. doi: 10.15171/hpp.2017.35. [PMID 29085796]

2. Ortega FB, Cadenas-Sanchez C, Lee D-c, Ruiz JR, Blair SN, Sui X. Fitness and fatness as health markers through the lifespan: an overview of current knowledge. Progress in Preventive Medicine. 2018;3(2). [PMID 32671316]

3. Ortega FB, Ruiz JR, Castillo MJ, Sjöström M. Physical fitness in childhood and adolescence: a powerful marker of health. Int J Obes. 2008;32(1):1-11. doi:10.1038/sj.ijo.0803774. [PMID 18043605]

4. Zeiher J, Ombrellaro KJ, Perumal N, Keil T, Mensink GBM, Finger JD. Correlates and determinants of cardiorespiratory fitness in adults: a systematic review. Sports Medicine - Open. 2019;5(1):39. doi:10.1186/s40798019-0211-2. [PMID 31482208]

5. Shephard RJ, Allen C, Benade AJ, et al. The maximum oxygen intake. An international reference standard of cardiorespiratory fitness. Bull World Health Organ. 1968;38(5):757-764. [PMID 5303329]

6. Grant JA, Joseph AN, Campagna PD. The prediction of VO2max: a comparison of 7 indirect tests of aerobic power. The Journal of Strength \& Conditioning Research. 1999;13(4). [PMID Not Available]

7. Kodama S, Saito K, Tanaka S, et al. Cardiorespiratory fitness as a quantitative predictor of all-cause mortality and cardiovascular events in healthy men and women: a meta-analysis. JAMA. 2009;301(19):2024-35. doi:10.1001/jama.2009.681. [PMID 19454641]

8. Sui X, Lee DC, Matthews CE, et al. Influence of cardiorespiratory fitness on lung cancer mortality. Med Sci Sports Exerc. 2010;42(5):872-8. doi:10.1249/MSS.0b013e3181c47b65. [PMID 19996990]

9. Ruiz JR, Sui X, Lobelo F, et al. Association between muscular strength and mortality in men: prospective cohort study. British Medical Journal (Clinical Research Edition). 2008;337(7661):a439-a439. doi:10.1136/bmj.a439. [PMID 18595904]

10. Institute of Medicine. Fitness Measures and Health Outcomes in Youth. Washington DC: The National Academies Press; 2012.

11. Mijnarends DM, Meijers JM, Halfens RJ, et al. Validity and reliability of tools to measure muscle mass, strength, and physical performance in community-dwelling older people: a systematic review. J Am Med Dir Assoc. 2013;14(3):170-8. doi:10.1016/j.jamda.2012.10.009. [PMID 23276432]

12. Celis-Morales CA, Welsh P, Lyall DM, et al. Associations of grip strength with cardiovascular, respiratory, and cancer outcomes and all cause mortality: prospective cohort study of half a million UK Biobank participants. BMJ. 2018;361:k1651. doi:10.1136/bmj.k1651 [PMID 29739772]

13. Mgbemena NC, Aweto HA, Tella BA, Emeto TI, Malau-Aduli BS. Prediction of lung function using handgrip strength in healthy young adults. Physiological Reports. 2019;7(1):e13960. doi:doi:10.14814/phy2.13960. [PMID 30632320]

14. Musalek C, Kirchengast S. Grip strength as an indicator of health-related quality of life in old age-a pilot study. The International Journal of Environmental Research and Public Health. 2017;14(12):1447. doi:10.3390/ijerph14121447 [PMID 29186762]

15. Sugie M, Harada K, Takahashi T, et al. Relationship between hand grip strength and peak VO2 in communitydwelling elderly outpatients. JCSM Clinical Reports. 2018;3(1):1-10. doi:10.17987/jcsm-cr.v3i1.48 [PMID Not Available]

16. Weir C, Jan A. BMI Classification Percentile and Cut off Points. Treasure Island, FL: StatPearls Publishing; 2021 [PMID 31082114].

17. Mani P, Sethupathy K, Francis AK. Test-retest reliability of electronic hand dynamometers in healthy adults. Int $J$ of Adv Res. 2019;7:325-31 [PMID Not Available].

18. MacDermid J, Solomon G, Fedorczyk J, Valdes K. Clinical assessment recommendations: impairment-based conditions. 3rd ed. Mt.Laurel, NJ: American Society of Hand Therapists; 2015. 
19. Uth N, Sørensen H, Overgaard K, Pedersen PK. Estimation of VO2max from the ratio between HRmax and HRrest-the Heart Rate Ratio Method. Eur J Appl Physiol. 2004;91(1):111-5. doi:10.1007/s00421-003-0988-y. [PMID 14624296]

20. Kobayashi H. Effect of measurement duration on accuracy of pulse-counting. Ergonomics. 2013;56(12):1940-4. [PMID 24117167]

21. Tanaka H, Monahan KD, Seals DR. Age-predicted maximal heart rate revisited. J Am Coll Cardiol. 2001;37(1):153156. doi:10.1016/S0735-1097(00)01054-8. [PMID 11153730]

22. Bandyopadhyay A. Prediction of maximum oxygen uptake by using the heart rate ratio method in Indian university students. Journal of Human Ergology (Tokyo). 2013;42(1-2):55-63. [PMID 25647946]

23. Craig CL, Marshall AL, Sjöström M, et al. International physical activity questionnaire: 12-country reliability and validity. Med Sci Sports Exerc. 2003;35(8):1381-95. doi:10.1249/01.mss.0000078924.61453.fb. [PMID 12900694]

24. Oyeyemi AL, Bello UM, Philemon ST, Aliyu HN, Majidadi RW, Oyeyemi AY. Examining the reliability and validity of a modified version of the International Physical Activity Questionnaire, long form (IPAQ-LF) in Nigeria: a crosssectional study. BMJ open. 2014;4(12):e005820-e005820. doi:10.1136/bmjopen-2014-005820. [PMID 25448626]

25. International Physical Activity Questionnaire. Guidelines for data processing and analysis of the international physical activity questionnaire (IPAQ) November 2005. Accessed December 15, 2020 https://docs.google.com/viewer?a=v\&pid=sites\&srcid=ZGVmYXVsdGRvbWFpbnx0aGVpcGFxfGd4OjEONDgxMDk3 NDU1YWRIZTM.

26. Onetti-Onetti W, Molina-Sotomayor E, González-Jurado JA, Castillo-Rodríguez A. Comparison between sexes of the relationships between body composition and maximum oxygen volume in elderly people. Sustainability. 2020;12(8):1-9. [PMID: Not Available]

27. Adedoyin RA, Ogundapo FA, Mbada CE, et al. Reference values for handgrip strength among healthy adults in Nigeria. Hong Kong Physiotherapy Journal. 2009;27(1):21-29. doi:10.1016/S1013-7025(10)70005-1. [PMD Not Available]

28. Piumi N, Jinali M, Janeesha N, et al. Descriptive study of hand grip strength and factors associated with it in a group of young undergraduate students in University of Peradeniya, Sri lanka who are not participating in regular physical training. International Journal of Physiotherapy. 2019;6(3)doi:10.15621/ijphy/2019/v6i3/183876. [PMID Not Available]

29. Sinha-Hikim I, Cornford M, Gaytan H, Lee ML, Bhasin S. Effects of testosterone supplementation on skeletal muscle fiber hypertrophy and satellite cells in community-dwelling older men. The Journal of Clinical Endocrinology \& Metabolism. 2006;91(8):3024-3033. doi:10.1210/jc.2006-0357. [PMID 16705073]

30. Verdijk LB, Snijders T, Drost M, Delhaas T, Kadi F, van Loon LJC. Satellite cells in human skeletal muscle; from birth to old age. Age. 2014;36(2):545-547. doi:10.1007/s11357-013-9583-2. [PMID 24122288]

31. Manoharan VS, Sundaram SG, Jason JI. Factors affecting handgrip strength and its evaluation : a systematic review. International Journal of Physiotherapy and Research. 2015;3(6):1288-93. doi:10.16965/ijpr.2015.193 [PMID Not Available]

32. Telford RM, Telford RD, Olive LS, Cochrane T, Davey R. Why are girls less physically active than boys? findings from the LOOK longitudinal study. PLoS One. 2016;11(3):e0150041. doi:10.1371/journal.pone.0150041. [PMID 26960199]

33. Al-Mallah MH, Juraschek SP, Whelton S, et al. Sex Differences in Cardiorespiratory Fitness and All-Cause Mortality: The Henry Ford Exerclse Testing (FIT) Project. Mayo Clin Proc. 2016;91(6):755-762. doi:10.1016/j.mayocp.2016.04.002. [PMID 27161032]

34. Loe H, Rognmo Ø, Saltin B, Wisløff U. Aerobic Capacity Reference Data in 3816 Healthy Men and Women 20-90 Years. PLoS One. 2013;8(5):e64319. doi:10.1371/journal.pone.0064319. [PMID 23691196]

35. Sharma HB, Kailashiya J. Gender Difference in Aerobic Capacity and the Contribution by Body Composition and Haemoglobin Concentration: A Study in Young Indian National Hockey Players. Journal of Clinical and Diagnostic Research. 2016;10(11):CC09-CC13. doi:10.7860/JCDR/2016/20873.8831. [PMID 28050360]

36. Burini RC, Anderson E, Durstine JL, Carson JA. Inflammation, physical activity, and chronic disease: An evolutionary perspective. Sports Medicine and Health Science. 2020;2(1):1-6. doi:10.1016/j.smhs.2020.03.004. [PMID Not Available]

37. Chung HY, Cesari M, Anton S, et al. Molecular inflammation: underpinnings of aging and age-related diseases. Ageing Research Reviews. 2009;8(1):18-30. doi:10.1016/j.arr.2008.07.002. [pmid 18692159]

38. Kullo IJ, Khaleghi M, Hensrud DD. Markers of inflammation are inversely associated with Vo2 max in asymptomatic men. J Appl Physiol. 2007;102(4):1374-1379. doi:10.1152/japplphysiol.01028.2006. [PMID 17170204]

39. Thompson D, Markovitch D, Betts JA, Mazzatti D, Turner J, Tyrrell RM. Time course of changes in inflammatory markers during a 6-mo exercise intervention in sedentary middle-aged men: a randomized-controlled trial. J Appl Physiol. 2010;108(4):769-779. doi:10.1152/japplphysiol.00822.2009. [PMID 20368384]

40. Roy JL, Hunter GR, Fernandez JR, et al. Cardiovascular factors explain genetic background differences in VO2max. Am J Hum Biol. Jul-Aug 2006;18(4):454-60. doi:10.1002/ajhb.20509. [PMID 16788902] 